\title{
A graphical approach to characterize sub-daily flow regimes and evaluate its alterations due to hydropeaking
}

\begin{abstract}
Most flow regime characterizations focus on long time scale flow patterns, which are not precise enough to capture key components of short-term flow fluctuations. Recent proposed methods describing sub-daily flow fluctuations are focused on limited components of the flow regime being unable to fully represent it, or on the identification of peaking events based on subjectively defined thresholds, being unsuitable for evaluations of short-term flow regime alterations through comparisons between regulated and free-flowing rivers. This study aims to launch an innovative approach based on the visual display of quantitative information to address the challenge of the short-term hydrologic characterization and evaluation of alteration resulting from hydropeaking. We propose a graphical method to represent a discrete set of ecologically relevant indices that characterize and evaluate the alteration of sub-daily flow regimes. The frequency of occurrence of classified values of a descriptive hydrological variable is represented in a map-like graph where longitude, latitude and altitude represent the Julian day, the value of the variable and the frequency of occurrence, respectively. Subsequently, we tested the method on several rivers, both freeflowing and subjected to hydropower production. The advantages of our approach compared to other analytical methods are: (i) it displays a great amount of information without oversimplification; (ii) it takes into account changes in the intensity, timing and frequency of the sub-daily flows, without needing a priori defined thresholds to identify hydropeaking events; and (iii) it supports the Water Framework Directive goal. Specifically, results from applications of our graphical method agree with Sauterleute and Charmasson (2014) analytical method.
\end{abstract}

\section{Introduction}

Hydropower is considered a clean, flexible, and renewable energy source, and the demand for hydropower is likely to increase as fossil fuels are phased out (e.g., by $40 \%$ until 2020 in Europe; Renöfält et al. 2010). In northern countries, climate change models predict future hydrographs to match power demands better, increasing the potential for 
producing more electricity (European Greenpower Marketing, 2006). Additionally, in certain regions such as Europe, hydropower is also being favored by legislation (e.g., the Renewable Energy Directive [RES; 2009/28/EC]) and the recently deregulated energy market. However, the global benefits of hydropower are accompanied by significant local impacts and environmental losses. Flow regime alteration constitutes a major impact from hydropower dam operation on fluvial ecosystems (Bunn and Arthington, 2002; Poff et al. 1997).

The deregulation and variable pricing in the electrical energy market gives hydroelectric producers an economic incentive to respond to rapidly changing electrical demands (Morrison and Smokorowski, 2000). Consequently, more hydropower installations are producing electricity using hydropeaking. Hydropeaking refers to rising or falling discharges caused either by the turning on or off of hydro-turbines to generate electricity according to variations in the market demand, often on daily or hourly time scales (Moog, 1993). As a result, downstream (Ibarra et al. 2015) and upstream river hydrology (e.g. Vollset et al. 2016) is altered due to rapid, frequent and significant fluctuations in discharge, which result also in unnatural changes in hydraulic parameters such as water level, flow velocity and bed shear stress, in water quality such as turbidity and temperature, and in river morphology. Although river flows vary on multiple temporal scales, from minutes to decades (Poff et al. 1997), it is the assessment of short-term changes in river flow (e.g., sub-daily flow variation) that is important for understanding the effects of hydropower generation dams on riparian and aquatic species and communities through hydropeaking (Meile et al. 2010; Zimmerman et al. 2010).

The majority of research to date has focused on flow variability at the daily, seasonal and longer time scales, and despite the numerous existing hydrologic indices (see review by Olden and Poff, 2003), most characterizations of flow regimes, quantitative measures of their alterations, and tools and software available today for calculations are based on daily-averaged flow records (e.g. Richter et al. 1996, 1997; Clausen and Biggs 2000; Baker et al. 2004; Gao et al. 2009; Carlisle et al. 2010; Fitzhugh and Vogel, 2011) which are not precise enough to capture key components of sub-daily flow fluctuation (Zolezzi et al. 2009; Zimmerman et al. 2010). Day-to-day and within-day water additions or losses in freeflowing rivers are ultimately caused by variations in rates of precipitation, evapotranspiration, infiltration and snowmelt, and by watershed characteristics (Lundquist and Cayan 2002; Archer and Newson 2002). These variations are small compared to the variability at annual 
time scales, but they have been shown also key for fish (see for example Saltveit et al. 2001) and macroinvertebrate (see for example Cereghino and Lavandier 1998).

Few indices have been very recently proposed to describe the sub-daily flow fluctuation. Most of them focus on certain components of the flow regime, hence being unable to fully represent it (Meile et al. 2011; Haas et al. 2014; Chen et al. 2015), and only some of them have already been used for the evaluation of sub-daily flow alterations (Zimmerman et al. 2010; Carolli et al. 2015). Sauterleute and Charmasson (2014), Bevelhimer et al. (2015) and Bejarano et al. (2016) developed a more thorough suite of indices quantifying the magnitude, the frequency and rapidity of flow changes during the day. Additionally, Sauterleute and Charmasson's indices provide information on the timing of the flow fluctuations and, together with those proposed by Bejarano et al. (2016), are the only indices which were applied to both discharge and water level. Differently to Bejarano et al. (2016) who focused on within-day hourly flow and level patterns, Sauterleute and Charmasson's methodology involves the identification of peaking events based on subjectively defined thresholds for the rate of change, making it unsuitable for evaluations of short-term flow regime alterations through comparisons between regulated and free-flowing rivers due to the unlikelihood of such peaking events in the latter.

Overall, traditionally devised hydrologic indices are analytic solutions to the problem of quantitatively describing the flow regime at different time scales. In order to properly characterize within-day hydrologic variation, there are a bunch of several key aspects of a within-day hydrograph which need to be quantitatively accounted (e.g., up to 62 hydrologic indices proposed by Bejarano et al. 2016), in the same way as up to 32 biologically relevant hydrologic parameters into five major groups (i.e., magnitude, timing, frequency, duration, and rate of change) are necessary to characterize intra-annual hydrologic variation (Richter et al. 1996). As many graphs (at least) as number of computed indices and usually large tables are commonly required to describe, explore, and summarize these sets of numbers. Consequently, the interpretation as a whole of such amount of information translated into numerical data is complex. Therefore, it is surprising that abstract, nonrepresentational pictures haven't been used yet in the field of hydrologic characterization to help interpretations (but see for example White et al. 2005). At their best, graphics are instruments for reasoning about quantitative information (Onwuegbuzie and Dickinson 2008). Furthermore, of all methods for analyzing and communicating large numerical information, 
well-designed data graphics are usually the most accurate and efficient, the simplest, and at the same time the most powerful (Tufte 2001).

Research on short-time scale flow regimes is still needed to devise a comprehensive, non-redundant suite of sub-daily flow metrics that adequately characterize within-day flow regime and evaluate its alteration, and which provides useful and easily understandable information for an environmental management of a hydropower plant (e.g., identifying environmental flow targets, prioritizing river restoration or dam reoperation efforts and contributing information for relicensing hydropower dams). Our main goal in this study relies on the powerful ability of humans to understand spatial information (Wainer 1992). We aim to launch an innovative approach based on the visual display of quantitative information to address the challenge of the short-term hydrologic characterization and evaluation of alteration. We first propose a graphical method to represent a discrete set of ecologically relevant indices that characterize and evaluate the alteration of sub-daily flow regimes. In this approach the frequency of occurrence of classified values of a descriptive hydrological variable (e.g. hourly flow, amplitude, rate of change, ...) throughout the year is represented in a map-like graph where longitude, latitude and altitude represent the Julian day, the value of the variable and the frequency of occurrence, respectively. A large number of hourly hydrographs can be represented by means of this type of graphs. Subsequently we test the method on several rivers, both free-flowing and subjected to hydropower production. Finally, we evaluate the advantages of our approach by comparing to other analytical methods.

\section{Methods}

\section{Graphical approach description}

Our graphical framework involves the representation of the values of variables that characterize relevant aspects of the short-term flow regime by describing its frequency during several years of observed values of such variable throughout the year. We propose a visual display of the frequency distribution of occurrence of all values of a descriptive variable along the year by means of a map-like graph where longitude (x axis) is the Julian day, latitude ( $\mathrm{y}$ axis) is the value of the descriptive variable and altitude ( $\mathrm{z}$ axis) is the frequency of a given value of the variable at a given day of the year. In order to build this graph, we first calculate the frequency distribution of a given variable at a given day (Fig. 1 
$[\mathrm{a}],[\mathrm{b}],[\mathrm{c}]$ ), and then plot together all the daily frequency distributions along the year (Fig. 1 $[\mathrm{d}],[\mathrm{e}],[\mathrm{f}])$.

The occurrence (i.e., frequency) of a given value class for a variable describing any particular aspect of a short-term flow regime is computed on a daily basis during several years in different selected river systems as the number of occurrences divided by the number of recorded hourly values for every Julian day in the year (e.g. for a nine-year study period: 27 occurrences in nine January $1^{\text {st }}$ gives a frequency of 27 occurrences / (9 days x 24 hourly records) $=0.125 \rightarrow 12.5 \%$ ). The number of classes into which the range of values of the variable is classified can be chosen by the user. It is even feasible to let class width be variable across the variable's range of values in order to build moderate resolution graphs (and to keep computational demands not too high). In our particular case, we arbitrarily classified the values of the variables into 20 classes of equal width, thus attaining a compromise between graphical resolution and computational requirements. In a rather long study period such as ours (9 years), values of the variables can eventually reach anecdotally extreme quantities. These outlayers might excessively enlarge the y axis and reduce the range in which the most frequent values are allocated. In order to avoid this inconvenience, we restricted our plotted dataset to variable values ranging between the percentiles 5 and 95 of all the observed values (including both altered and free-flowing data series). We used this method to calculate 366 daily frequency distributions (February 29 , was coded "non-available (NA)" when not existing) (Fig. 1 [a], [b] and [c]), and we plotted them together along the year (x-axis) (Fig. 1 [d], [e] and [f]). Since the observed frequencies of the variables may vary abruptly among two adjacent observations, the plot would appear as a spiky surface showing many scattered peaks. This raw map would be precise, although much of the information on the general trends of the frequency distribution would be blurred by the original noise of the data. However, our main purpose is to provide a visual display of all the information keeping as many facts as possible concerning the complete dataset. Therefore, a compromise must be reached between precision and usefulness. In order to facilitate the graphical interpretation of the distribution of occurrences of the variable's values along the year, a smooth approximation by means LOESS [fitting a polynomial surface determined by one or more numerical predictors, using local fitting (Cleveland et al. (1992)] of frequencies (z) against variable value $(y)$ and Julian day $(x)$ is plotted. Weighted least squares fitting is done locally, meaning that for the fit at point $x$, the fit is made using points in a neighborhood of $x$, weighted by their distance from $x$. A parameter $\alpha$ controls the degree of the smoothening, by controlling the size 
of the neighborhood. For $\alpha<1$, the neighborhood includes an $\alpha$ proportion of the points, and these have tricubic weighting (proportional to $\left.\left(1-(\text { distance/maximum distance })^{3}\right)^{3}\right)$. For $\alpha>1$, all points are considered, with the 'maximum distance' assumed to be $\alpha^{(1 / p)}$ times the actual maximum distance for $p$ explanatory variables. In our particular case we used a low smoother module $(\alpha=0.05)$. As in cartography, the scale of the map determines its precision, therefore $\alpha$ can be set inversely proportional to the width of the variable's classes.

The smoothening and the representation was conducted by means of the levelplot function, panel.2dsmoother at library (latticeExtra) in R (R Core Team 2016).

The resulting plots (Fig. 1 [d], [e], [f]) show that, during winter and autumn, high values of the variable are more frequent in impaired (hydropeaking, Fig. 1 [d]) than in free-flowing conditions (Fig. 1 [e]). Graphically, it may be interpreted that the impacted (hydropeaking) conditions reduce the frequency of low values of the variable (as if there was a deficit of low values) -and, subsequently, there is an increase in the frequency of higher values (a surplus of high values)- during winter and autumn (Fig. 1 [f]). To quantify the effect of surplus and deficit in the impact graph it is feasible to define the volume they generate, which is namely the area (days $\mathrm{x}$ variable value) times the average height (frequency). The position of the surplus volumes relative to the deficit volumes along the gradient of the variable (y axis) comprises a distance. High values of this distance mean that the variable's values that are more (or less) frequent in altered conditions are very different from those values that should be more (or less) frequent in free-flowing conditions. Therefore, the larger is this difference, the greater is the impact.

These map-like graphs can be used as instruments for the interpretation of the large amount of quantitative information included in hourly hydrographs concerning several years. These contain a significant amount of information that can be interpreted in a simple and intuitive way, and without requiring oversimplification. In the example shown in Fig. $1[\mathrm{e}]$, it may be noticed that the lowest values of the variable are registered during late autumn and winter. This period is followed by a season in which the variable's values are highly dispersed between 0.5 and 4, reaching a peak in late spring. The variable's values become more concentrated around lower values as summer conditions lead the flow towards the lower values achieved in autumn. It is also noticeable that events with high variable values are extremely rare during the winter, but can occur in early autumn.

This visual display also allows the use of well-known concepts, such as cartographic tools, so as to interpret the ample information which is comprised. Short-term 
flow regime characterization and hydropeaking impact assessment can be intuitively addressed by applying the aforementioned graphical approach to sub-daily (e.g., hourly) flow records of free-flowing rivers and rivers affected by hydropeaking. In the example, we compare the graphs obtained from altered (i.e. affected by hydropeaking schemes) (Fig. 1 [d]) vs. free flowing (Fig. 1 [e]) conditions. If the surfaces represented in these graphs were interpreted as landscapes, when both landscapes are compared, a difference in the distribution of elevations may occur. This difference can be calculated by subtracting the $\mathrm{z}$ values of the free flow graph (Fig. 1 [e]) from those of the altered graph (Fig. 1 [d]). The resulting elevations can also be plotted using the same XY axes (Fig. 1 [f]), thus exhibiting areas with positive and negative elevations. Positive elevations correspond to days in which the frequency of a given value of the variable is higher in altered conditions, whereas negative elevations mean that, for a given day, the frequency of occurrence of a particular value of the variable is higher in free flowing than in altered conditions. It may be expected that in these sort of graphs an unimpaired site would show a flat zero-elevation landscape. On the contrary, a heavily impacted site would produce a graph showing an abrupt landscape. As already mentioned, the difference between the most frequent values of the variable in altered vs. free flow conditions at a given day is also an indicator of impact. This aspect of the impact is reflected by the distance (in y axis) among the elevations and the depressions in the impact graphs (Fig. 1 [f]). The larger the distance, the greater is the difference between the most frequent values of the variable in altered vs. free flow conditions. Thus, it is possible to obtain a quantitative indicator of the impact by taking into account both of its components: $\left(1^{\text {st }}\right.$ component) the difference of elevations ( $\mathrm{z}$ axis) at a given day for a given variable value; and ( $2^{\text {nd }}$ component) the distance (y axis) between the most frequent value of the variable at a given day in altered vs. free flow conditions. Following the analogy with cartography, such consideration simulates the calculation of the effort required to move the elevated lands so as to fill the depressions in an abrupt ( impacted) landscape and level it into a flat zero-elevation ( unimpacted) terrain. In order to perform such computation, we first calculate the impact on a daily basis, and then average the daily results for the whole year to obtain a synthetized value of the difference between altered and free flow conditions. Once the frequencies for the variable have been calculated for every Julian day, the difference of frequencies ( $\mathrm{y}$ axis in Fig. $1[\mathrm{a}],[\mathrm{b}]$ ) for a given value class of the variable (x axis in Fig. $1[a],[b]$ ) at a given day of the year (day $i$ ) is calculated between the altered (Fig. 1 [a]) and the free flow conditions (Fig. 1 [b]). This result provides the value of the $1^{\text {st }}$ component of the impact. The $2^{\text {nd }}$ component of the impact can be measured by the existing distance, $D_{\text {day } i}$, between the positive and the 
negative values of the daily frequency distribution of the variable (Fig. 1 [c]). This can be done by calculating the distance between the correlative center of masses of both the positive and negative sections of the graph. The center of masses of the positive (and, correspondingly, the negative) components is calculated as the average value of the variable ( $\mathrm{x}$ axis in Fig. 1 [a], [b]) weighted by the values of the frequency (y axis in Fig. 1 [a], [b]) of the variable

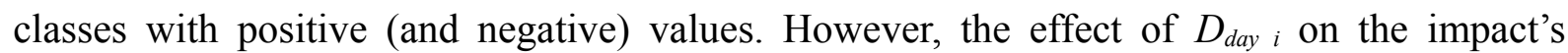
estimation should be relative to the range of variation of the variable in free-flowing conditions. Therefore, the input of $D_{\text {day } i}$ in the impact calculation is divided by the difference between percentile 95 and percentile 5 of the considered variable's values observed at freeflowing conditions. This range of percentiles is noted as $r$.

To synthetize both components, the impact of the hydropeaking scheme in every variable at a given day $i$ is calculated as the average of the area (calculated as the average value of the positive, or negative, frequencies, times the number of variable classes with positive, or negative, frequencies) of positive values $\left(A_{\text {pos. }}^{\text {day } i} i\right)$ and the area of negative values $\left(A_{\text {neg }}^{\text {neg }} i\right)$ times the ratio of the distance between the respective centers of masses $\left(D_{\text {day }} i\right)$ and the range among percentiles 5 and 95 of the variable at free-flowing conditions for the complete study period ( $r$ ) (Equation (1); Fig. 1[c]). The average value of the daily impacts along the year is assumed to be a good estimate of the global impact for the considered variable (Equation (2)).

$$
\begin{aligned}
\operatorname{Impact}_{\mathrm{day} i} & =\frac{A_{\mathrm{day} i}^{\mathrm{neg} .}+A_{\mathrm{day} i}^{\text {pos. }}}{2} \cdot \frac{D_{\mathrm{day} i}}{r} \\
\text { Impact } & =\frac{\sum_{1}^{365} \operatorname{Impact}_{\mathrm{day} i}}{365}
\end{aligned}
$$


Short-term flow regime characterization and hydropeaking alteration assessment

With the objective of testing the graphical approach, we applied the method to several river reaches in northern Sweden (boreal), western USA (continental) and northern Italy (alpine), representing different hydropeaking schemes and intensities (from free-flowing to highly regulated by hydropower plants). Sub-daily flow records at selected reaches at time intervals ranging from several minutes to one hour during a nine-year period were gathered. For calculations, we homogenized the time interval of the flow series to 1-hour intervals in all study cases. We also selected the 2003-2011 period of flow records from comparable pairs of river reaches, unimpaired (i.e. free-flowing) and impaired (affected by hydropeaking devices), from Sweden and Italy, whereas we used the flows from 1943 to 1951 and 2003 to 2011 from the same river reach in USA as free-flowing and hydropeaking conditions, respectively. Selected river reaches and characteristics are detailed in the Table 1. Sub-daily flow records were obtained from the Swedish Meteorological and Hydrological Institute (SMHI, Sweden), the Grand Canyon Monitoring and Research Center (USGS, USA), and the Servizio Prevenzione Rischi of the Autonomous Province of Trento (Italy). We selected four metrics from those commonly used in the literature to describe both long- (Richter et al. 1996) and short-time scale (e.g., Bejarano et al. 2016) hydrographs which describe key aspects (i.e., magnitude, frequency and rate of change) of a within-day flow hydrograph as variables for graphical representations. Four metrics were selected to describe key aspects (i.e., magnitude, frequency and rate of change) of a within-day flow hydrograph from the already proposed quantitative metrics in the literature (Bejarano et al. 2016) as variables for graphical representations. Selected variables were:

(1) Standardized hourly flow, Qst [unitless], calculated as the observed value divided by the hourly mean flow of the study period in the same conditions (altered or free flow). We used the standardized hourly flow by dividing it by the hourly mean flow value of the complete study period ( 9 years) for the calculation of all variables. Standardized flows are not necessary unless there is a difference of mean discharge between altered and free flow conditions. This was the case of Colorado river, which experienced a reduction in the mean discharge between the free flow period 1943-51 $\left(465 \mathrm{~m}^{3} \mathrm{~s}^{-1}\right)$, and the altered period 2003-11 $\left(358 \mathrm{~m}^{3} \mathrm{~s}^{-1}\right)$. Therefore, in order to use consistent units in the whole the study, we utilized standardized hourly flow values for all the sites. 
(2) Daily amplitude of recorded hourly flows, amplitude_Qst [unitless], calculated as the daily maximum standardized hourly flow minus its minimum. This variable has a daily resolution (one observation per day).

(3) Rate of flow decrease between two consecutive hourly records, decrease_slope_Qst $\left[\mathrm{h}^{-1}\right]$, calculated as the standardized hourly flow in time $h$ minus the standardized hourly flow in time $h-1$ (only decreasing trends have been considered in the analyses); and

(4) number of hourly flow reversals (decrease to increase, and increase to decrease) per day, reversals_day, considering every change in the trend among every three consecutive records as a reversal. We did not consider any threshold to define a reversal since our main interest was to maintain as much information as possible. Consequently, the results are a mere description of the conditions which are experienced by the elements of the ecosystem, regardless of their sensitiveness or response to different degrees of alteration. We thus accounted the total number of reversals experienced by the hydrograph at a given day. This variable has, therefore, a daily resolution.

The metrics "hourly flow" and "daily amplitude of hourly flows" provide information on the magnitude of the flow; the latter implies the identification of the highest and the lowest hourly discharge for each day. The metric "rate of decrease of hourly flows" provides information on the abruptness and number (i.e., rate and frequency) of intra-day flow change. Finally, the "number of hourly reversals" contributes awareness concerning the frequency of hourly flow switches from a rising to a falling trend (and vice versa) within each day.

The computational tool proposed in Sauterleute and Charmasson (2014) was utilized in order to contrast its results with those obtained by means of the graphical method. We used the same flow records and standardized procedures as in our graphical approach. The tool's algorithm is based on an iterative process in which an initial threshold $c$ is established for both increase and decrease conditions. A threshold standardized slope is then calculated for each situation by multiplying the maximum standardized incremental or decremental slope by its threshold (either $c_{i n c}$ or $c_{d e c}$ respectively). If the slope of the flow curve at instant $t$ equals or exceeds the increase threshold slope, or is lower than or equals the decrease threshold, the occurrence of a hydropeaking increase or decrease condition is registered. After the flow values for the complete set of time intervals have been evaluated and categorized, the maximum and minimum standard flows are calculated for each increase and decrease 
sequence, and a graphic representation is performed. A visual inspection is then implemented so as to determine if the provisional threshold values provide an appropriate identification of the hydropeaking events. If so, the algorithm ends. In case further refinement is necessary, threshold values $c$ decrease by a predetermined amount and a new iteration begins. Once the iterative loop finalizes, a comprehensive set of parameters to characterize hydropeaking magnitude, time and frequency features is calculated, and a statistical analysis is subsequently implemented. In all cases, parameters $d$ which limits the minimum duration for a peaking sequence to be considered is 120 minutes, $T$ for multipeaking sustained flow analysis is 2 hours, and fraction $p=0.2$ is used in the algorithm's decision tree. The values for parameters $T$ and $p$ are equivalent to those used in Sauterleute and Charmasson (2014). However, the value used for parameter $d$ is 120 minutes (in practice 1 hour, since for hourly-collected data, the algorithm's condition disregards peaking events strictly shorter than two hours), while $d$ is 45 minutes in the aforementioned article because its case study assesses data which has been registered in 15 minute intervals.

The tool's output information is complemented with additional variables to enable the comparisons with the results obtained when using the proposed graphical approach. Similarly to the variables used to test the graphical approach, the variables selected from Sauterleute and Charmasson (2014) represent flow magnitudes, rates of change and frequencies: (1) The peaking amplitude is obtained by using the average standardized flow ratio of the rapid decreases, $\bar{F}_{\text {dec,std }}$ (Equation (3)). The total amount of decrease sequences is $n_{d}$, and $Q_{\text {max, n,dec }}$ and $Q_{m i n, n, d e c}$ represent the upper and lower standardized flow values for each of the $n$ decrease phases, respectively. (2) The rate of changes in flow is assessed using the average value of the mean rates of standardized flow decrease, $R_{\mathrm{Qm}, \mathrm{dec} \text {,std }}$ as expressed in Equation (4). $t_{e, n, d e c}$ represents the end time of decrease sequence $n$ and $t_{s, n, d e c}$ its starting time. (3) Finally, peaking frequency is evaluated by counting the average number of daily rapid decreases, $\bar{N}_{d \text {, dec, std }}$.

$$
\begin{gathered}
\bar{F}_{\mathrm{dec}, \mathrm{std}}=\frac{1}{n_{d}} \sum_{n=1}^{n_{d}} \frac{Q_{\mathrm{max}, n, \mathrm{dec}} / Q_{m}}{Q_{\mathrm{min}, n, \mathrm{dec}} / Q_{m}}=\frac{1}{n_{d}} \sum_{n=1}^{n_{d}} \frac{Q_{\mathrm{max}, n, \mathrm{dec}}}{Q_{\mathrm{min}, n, \mathrm{dec}}} \\
\bar{R}_{\mathrm{Qm}, \mathrm{dec}, \mathrm{std}}=\frac{1}{n_{d}} \sum_{n=1}^{n_{d}} \frac{\frac{Q_{\mathrm{max}, n, \mathrm{dec}}-Q_{\mathrm{min}, n, \mathrm{dec}}}{Q_{m}}}{t_{e, n, \mathrm{dec}}-t_{s, n, \mathrm{dec}}}
\end{gathered}
$$


Regressions have also been developed between the impact value for each of the variables calculated by applying the graphical approach, and the equivalent results obtained when using the method described in Sauterleute and Charmasson (2014).

\section{Results}

Our graphical approach produces two sorts of results: a graphical display and a quantitative value of the impact. A visual display of the data in the form of a map-like graph shows a general picture of the distribution of the frequencies of occurrence of different values of a variable throughout the year. This feature allows the observer to perceive a large amount of information in just a few graphs. Such results can also be described by using similar terminology as cartography utilizes to describe a landscape. Different observers, with different interests, will focus on different aspects of the graphs, and would eventually describe them in the same way. However, any textual description would be much less efficient than the graphical display; and will always cause oversimplification. The interpretation of the graphs comes next. Just like maps, we need tools to quantify these different aspects. In our particular case, we calculated the difference between the graphs describing altered and free flow conditions, and used this quantification to produce a rough general numerical value of the synthesized difference. It is therefore important to highlight that both results are complementary; the graphical display provides an insight of the whole set of results, whereas the impact value provides objectiveness to the interpretation of a particular aspect of the results (namely the quantitative impact of hydropeaking).

The results from the graphical analysis of the hourly flows (i.e., variable (1); Fig. 2a, 3a, 4a, 5a) mirror the hydrological alteration resulting from upstream dams at a longer time scales (e.g., seasons). Seasonal patterns of hourly flows in free flowing rivers are clearly shown as more or less low winter flows and high spring flows, mainly depending on the climatologic traits of each river. Flow regulation dramatically changes these seasonal patterns in the Ume (Harrsele dam) and Colorado Rivers (Figs. 2a and 4a), whereas it slightly impacts the seasonal hourly flows pattern in the regulated Noce River (Fig.5a) which is similar to the free-flowing pattern of the Vermigliana River. Additionally, the results from the graphical analysis of the remaining variables related to the magnitudes, rates of change and frequencies (variables (1), (2) and (3)) evaluate hydropeaking effect traits at a shorter time scale. Hourly flow amplitude, rate of change and reversals remain around zero along the entire year in the free-flowing Swedish reaches (in the Vindel River; Figs. 2b, c, d and 3b, c, d), whereas they 
become more variable along the year according to a seasonal pattern in the naturally flashiest rivers (i.e., the Colorado pre-impact and the Vermigliana Rivers; Figs. 4b, c, d and 5b, c, d). For example, the amplitude in the Vermigliana River has a wider range of values during summer, while these concentrate nearby low values in fall and winter. The number of hourly reversals of the Colorado River during the pre-impact period and the Vermigliana River fluctuates around 2 and 5 (median values) per day, respectively. In general, hydropeaking schemes increase the range of variability of all variables and laminate or eliminate the seasonal pattern. As the hydropeaking intensity increases, as occurs in the Swedish case (in the Ume River; Figs. 2 and 3), less signs of seasonality are found, whereas seasonality is still slightly seen under altered conditions in the less impacted cases (e.g., the Colorado postimpact and the Noce Rivers; Figs. 4 and 5).

The relative position of the deficit and surplus volumes in the impact graphs along the gradient of the variable (y-axis) shows the difference between the most frequent values of a variable in free-flowing and altered conditions. For example, the fact that the most frequent amplitude and number of reversals in the free-flowing conditions is close to zero in the Granaker reach (i.e., lower Vindel River; Fig. 2c, d) results in a deficit volume (blue colored) at the bottom of the impact graph for the pair Harrsele-Granaker. The mode of the amplitude is 1.7 during the complete year under the altered conditions characterizing the Harrsele reach (i.e., lower Ume River), thus resulting in a surplus volume in the impact graph (brownish colored) around this value. Therefore, both surplus and deficit volumes are separated by a distance of more than 1.5 units in the y-axis. Since the natural range of variation $(r)$ is very low in the lower Vindel River, the effect of such distance is very high. Contrarily, when the ratio becomes smaller because of a high $r$ value, the influence of the distance is much lower, thus resulting in a lower impact. For instance, regardless the height and depth (z-axis) of the surplus and deficit volumes in the Colorado pre and post impact graph for the amplitude (Fig. 4c), their relative distance is similar to the natural range of variation, thus resulting in a lower impact. If cartographical terms are used to describe and compare the information contained in the impact graphs for the amplitude, a continuous mountain range (very frequent values) and coastline (edge between surplus and deficit volumes) throughout the year is evidenced in the rivers which are highly affected by hydropeaking. As we move towards less impacted reaches, the landscape becomes more heterogeneous, the coastline and mountain ranges are more variable, and what is more 
relevant for our purpose of impact assessment, the highest peaks get closer to the lowest depressions. Finally, at the least impacted reach (the Noce River), the high and deep areas are moderate and are closer to each other than in more impacted reaches. In terms of impact, the lowest the difference between the high volumes and deep depressions, and the closer the distance to each other, the less impact.

If the same approach is used to describe the rate of flow change, it may be noticed that its values remain fluctuating close to zero under hydropeaking conditions, like in free-flowing conditions, but with a wider distribution of values along the year. This produces a gently-sloping landscape in the impact graphs of the rate of flow change, with a large almost flat plateau, and a deep regular depression at the top of the graph.

The impact value for each of the considered variables calculated by applying the graphical approach is coherent with those presented by Sauterleute and Charmasson (2014) (Table 2). Linear regression models of the form $\mathrm{S}$ (variable) $=\mathrm{aGM}($ variable) $+\mathrm{b}$, where $\mathrm{GM}$ (variable) is the hydropeaking impact for a given variable using our graphical approach (GM) and S(variable) is the analogous metrics identified using Sauterleute and Charmasson (S) (see Table 2 for data and details), were fitted between both types of impact values. The models showed reasonably good fitting; with $\mathrm{R}^{2}$ of $0.9,0.7$ and 0.6 for the amplitude, rate of decrease and reversals, respectively (standardized hourly flow was not included in this comparison because there is not an analogous variable in Sauterleute and Charmasson (2014)). Coefficients of the fitted models were: amplitude $a=14.4, b=-1.8$; rate of decrease $\mathrm{a}=0.01, \mathrm{~b}=0.07$; and reversals $\mathrm{a}=0.12, \mathrm{~b}=0.72$.

The values for Sauterleute and Charmasson's (2014) variable $F_{\text {dec }}$ indicate that the highest peaking amplitudes occur for the Ume River, and these are significantly higher than those obtained for the Colorado and Noce Rivers (Table 2). This circumstance is primarily caused by the low minimum flow values at the Swedish river and its limited regulation capacity (Table 1). In fact, the regulated flow presents rather frequent zero-flow conditions (especially at the Harrsele gauge, where the Ume is highly impacted). This particular case highlights a limitation which may arise when using this variable, since zero division ratios may occur. As this has been the case for the Ume River, the parameter's value for this river was computed excluding these particular events, and, even so, final values for Ume are extremely high. Lower $\bar{F}_{\text {dec }}$ values are obtained for both the American and Italian rivers, although their hydropeaking features differ significantly due to the dissimilarities in the power generation strategy and the hydrological characteristics of each water stream (Table 1). 
In the case of the Colorado, lower peaking amplitudes are obtained primarily due to rather conservative minimum flow values (much higher regulation capacity than the others; Table 1). For the Noce River, these variable's results are influenced by the river's limited regulation capacity (Table 1). Consequently, its hydropeaking events are planned in synchrony with the baseline flow, which attenuates this variable's value, especially when flows exceed the average value. Concerning the results obtained for the mean rate of normalized flow decrease, variable $R_{\mathrm{dec}}$ again reaches the highest values for the Swedish river. Likewise, the aforementioned regulation peculiarities affecting the American and Italian rivers influence their respective rate of flow decrease, for which the Colorado River presents the lowest value. Counting of rapid daily decreases provides additional information on each river's hydropeaking peculiarities. While Ume-Harrsele and Colorado Rivers are exposed to approximately one complete daily decrease, such ratio is 0.62 at Ume-Grundfors and 0.66 for the Noce River.

\section{Discussion}

Short-term flow regimes have not been studied in depth partly because of the unavailability of long time series of short-interval hydrologic data (Zimmerman et al., 2010), but also due to the tedious management, representation and interpretation of such amount of information (Tufte 2001). The maxim "a picture is worth a thousand words" has inspired the development of the graphical approach introduced in this article. The graphical approach consists in a three-dimensional (i.e., time, variable value, and variable frequency) map-like graphical representation of any variable, enabling large data set management, description, exploration, tabulation and comparison. When applied to sub-daily flow data, it may be used to represent any variable describing ecologically relevant aspects of the short-term flow regime (according to Poff et al. (1997)) hence, allowing the rivers' short-term flow regime characterization, both free-flowing and regulated (e.g., subjected to hydropeaking). Furthermore, by facilitating the comparison of the free-flowing and regulated graphical patterns from the same river reach or from similar rivers, this approach allows the evaluation of the deviation from the $u n$ altered conditions (e.g., intensity of hydropeaking alteration). The resulting graphical signatures may be seen as fingerprints exclusively corresponding to the studied rivers, revealing information on their short-term flow regime and their degree of alteration. In rivers with hydropower plants, we assume that particular electricity demands and hydraulic infrastructures 
superimposed on the river flow regime determine the river's sub-daily flow alteration which is represented by a hydropeaking fingerprint.

The graphical approach improves recently proposed analytical methods (Zimmerman et al. 2010; Meile et al. 2011; Haas et al. 2014; Sauterleute and Charmasson 2014; Bevelhimer et al. 2015; Carolli et al. 2015; Chen et al. 2015; Bejarano et al. 2016) which aim sub-daily flow characterizations. Traditional analytical methods are based on too many variables usually summarized in large tables that are difficult to understand at a glance, whereas visual displays enable the illustration of a large flow data set in a small space, making data coherent, and encouraging the eye to compare diverse data components at different levels of detail. Furthermore, visual displays avoid distorting data interpretation, and induce the viewer to think about the substance rather than something else (Tufte 2001). On the other hand, by superimposing the sub-daily flow fingerprint from two comparable free-flowing and altered river reaches, the approach allows to quantify and represent the variability of the impact on a graph with clarity, precision and efficiency. In general, already proposed analytical methods such as Sauterleute et al. (2014), do not provide a degree of alteration analysis.

Hydropeaking results in important changes in all analyzed variables referring to magnitudes, rates of change and frequencies of sub-daily flows. Impact graphs obtained by applying the graphical approach evidence the manner in which changes in the frequencies of sub-daily flow variables occur throughout the year. To take advantage of all the amount of information contained in the output graphs, these may be interpreted as topographic maps. According to this analogy, the impact graphs for amplitude and number of hourly reversals per day exhibit an abrupt 'landscape' characterized by high hills. This is because higher values for amplitude and reversals become more frequent and their distribution throughout the year is also altered under hydropeaking when compared to the free-flowing conditions (which remain around zero). The heterogeneity of these 'landscapes' throughout the year (i.e. the presence of a rough coastline, and abrupt separated hills and depressions) indicates the different degree of impact that is produced by hydropeaking schemes at different seasons.

Our results show that, under a similar intensity of hydropeaking, a more naturally stable river, such as the boreal ones in our case, would be much more hydrologically affected by hydropeaking than a naturally flashy river, such as the alpine river. According to the habitat template concept (Southwood 1977) biotic communities are determined by the natural disturbance regime at their respective habitats. Therefore, ecological changes to hydrological 
alteration derived from hydropeaking might be expected to be greater in naturally stable rivers than in naturally flashy streams.

The quantitative value of the impacts provided by the graphical approach is consistent with the characterization of the hydropeaking events made when using the approach proposed by Sauterleute and Charmasson (2014). The application of the Sauterleute and Charmasson's computational tool indicates that the most impacted river is the Ume at Harrsele site, with high relative peaking amplitudes and slopes. Upstream at Grundfors, the amplitude of the events is proportionally similar, although with lower slopes and minor frequency. The Colorado River power plant operates with inferior relative peaking amplitudes (highest regulation capacity), the mildest flow-decrease slopes, and an average of nearly one daily decrease. This operation scheme is partly conditioned by this plant's high generation capacity and the huge eight turbines used for energy production. Finally, the Noce seems to be the least affected river, with the plant's unit dispatch following the stream's baseline flow with both moderate amplitudes and slopes, and lower daily number of decrease sequences. It must be noticed that our selected variables and Sauterleute \& Charmasson 's flow variables are not the same, and consequently our comparison of approaches should not be considered a validation of our method. However, both sets of variables represent analogous aspects of the flow regime, such as magnitude, frequency and rate of change; thus providing evidences that both approaches are measuring the same effects. In contrast, the graphical method additionally takes into account the timing and the frequency of occurrence of the events throughout the year. This might be especially relevant due to the fact that hydropeaking changes the intensity of the flow variable, but also its timing and frequency distribution. This temporal magnitude allows a ponderation of the impacts produced by hydropeaking according to the different fragility and sensitiveness of the biotic communities to short term flow fluctuations throughout the year. Moreover, by taking into consideration all the range of values of a flow variable, instead of using previously defined thresholds to identify hydropeaking events, it is also possible to weight the effect of the changes for different values of the considered variable. It is therefore feasible to apply a weighting grid (analogous to the curves defined in the International standard IEC 61672:2003 applied to the measurement of sound pressure level) to the observed change in the frequency of occurrence of the different values of a variable across the year, so as to account for the relative impact experienced by the different biotic components of the ecosystem throughout their life cycle (Parasiewicz 2008). This approach may also be 
used as a basis for estimating the environmental costs that hydroelectric production originates through hydropeaking. Certainly, once the hydrological alteration caused by hydropeaking is quantified, an environmental price to hydrologic alteration unit can be justified as has been accomplished in other research studies, such as García de Jalón et al. (2015), and thereby, environmental costs derived from hydropower generation can be assessed. By applying this approach to characterize and evaluate sub-daily flows from individual years, it is possible to identify critical periods of the year in which the high intensity of hydroelectric production is causing major hydrologic alteration.

Analytical indices for flow alteration evaluation are designed to simplify information in their aim to quantitatively answer a few well defined questions with a limited set of values. Just like maps, a visual display of a large set of results keeps much of the information contained in it, and allows raise a larger set of questions. This might provide a framework for different stakeholders to extract specific information from a common description of hydrological conditions, according to their interests and expertise. Analogously, different elements of the ecosystem (e.g. biota, hydromorphology) might be sensitive to different aspects of the impacted conditions. Keeping a large amount of information (including timing, intensity and frequency of occurrence of a set of descriptive variables), as well as the lack of a priori stated thresholds, can be an advantage in holistic studies aiming at considering the different sensitiveness of the ecosystem's diverse agents to the alteration of hydrological conditions.

Variability among perceivers can be, however, a weakness of this kind of visual representations (Macdonald-Ross 1977). Different observers with different experience might have different perceptions of the same area (Tufte 2001). Just as maps, it needs tools to infer precise and objective answers to defined questions. Besides, it lacks the ability to be applied to such a large and diverse set of variables as those present in more analytical methods (Sauterleute and Charmasson 2014; Bejarano et al. 2016), since the variables should be defined in previously delimited time steps (e.g. days in our case; or weeks in a coarser time scale). However, our graphical approach provides an insight to a detailed description of the results which, combined with other methods, can be used by the different stakeholders in order to meet compromises over a common template.

\section{Acknowledgments}


We acknowledge the RiPeak (Ref.623691) project for financial support through the EU-FP7- Marie Curie IEF Actions. We thank the Swedish Meteorological and Hydrological Institute (SMHI) and the hydropower companies Statkraft Sverige AB and Vattenfall AB in Sweden, the Rete di monitoraggio in tempo reale dell'Ufficio DigheServizio Prevenzione rischi of the Autonomous Province of Trento in Italy, and the Grand Canyon Monitoring and Research Center (USGS) in USA, for providing sub-daily flow series. We also appreciate the assistance of Roland Jansson and Jack Schmidt to collect flow data.

\section{References}

Archer, D., Newson, M. 2002. The use of indices of flow variability in assessing the hydrological and instream habitat impacts of upland afforestation and drainage. Journal of Hydrology, 268(1), 244-258.

Baker, D. B., Richards, R. P., Loftus, T. T., Kramer, J. W. 2004. A new flashiness index: Characteristics and applications to midwestern rivers and streams.

Bejarano, M.D., Sordo-Ward, A., Alonso, C., Nilsson, C., Jansson, R. 2016. Assessing the effects of hydropower dam operations on short-term flow regimes. Proceedings of the Congress SHF: HydroES 2016. Grenoble, France, 16-17 March.

Bevelhimer, M. S., McManamay, R. A., O'Connor, B. 2015. Characterizing Sub-Daily Flow

Regimes: Implications of Hydrologic Resolution on Ecohydrology Studies. River Research and Applications, 31(7), 867-879. 
Biggs, B. J., Nikora, V. I., Snelder, T. H. 2005. Linking scales of flow variability to lotic ecosystem structure and function. River Research and Applications, 21(2-3), 283-298.

Bunn, S. E., \& Arthington, A. H. 2002. Basic principles and ecological consequences of altered flow regimes for aquatic biodiversity. Environmental management, 30(4), 492-507.

Carlisle, D. M., Falcone, J., Wolock, D. M., Meador, M. R., Norris, R. H. 2010. Predicting the natural flow regime: models for assessing hydrological alteration in streams. River Research and Applications, 26(2), 118-136.

Carolli, M., Vanzo, D., Siviglia, A., Zolezzi, G., Bruno, M. C., Alfredsen, K. 2015. A simple procedure for the assessment of hydropeaking flow alterations applied to several European streams. Aquatic Sciences, 77(4), 639-653.

Cereghino, R., Lavandier, P. 1998. Influence of hydropeaking on the distribution and larval development of the Plecoptera from a mountain stream. Regulated Rivers: Research \& Management, 14(3), 297-309.

Chen, Q., Zhang, X., Chen, Y., Li, Q., Qiu, L., Liu, M. 2015. Downstream effects of a hydropeaking dam on ecohydrological conditions at subdaily to monthly time scales. Ecological Engineering, 77, 40-50.

Clausen, B., Biggs, B. J. F. 2000. Flow variables for ecological studies in temperate streams: groupings based on covariance. Journal of Hydrology, 237(3), 184-197.

Cleveland, W.S., Grosse, E. Shyu, W.M. 1992. Local regression models. Chapter 8 of Statistical Models in S eds J.M. Chambers and T.J. Hastie, Wadsworth \& Brooks/Cole.

European Greenpower Marketing. 2006. Hervorragende Aussichten für Wasserkraft: www.greenpowermarkets.eu/

Fitzhugh, T.W., Vogel, R.M. 2011. The impact of dams on flood flows in the United States. River Research and Applications 27: 1192-1215.

Gao, Y., Vogel, R. M., Kroll, C. N., Poff, N. L., Olden, J. D. 2009. Development of representative indicators of hydrologic alteration. Journal of Hydrology, 374(1), 136-147. 
García de Jalón, S., González del Tánago, M., Alonso, C., García de Jalón, D. 2015. Evaluating the environmental costs of flow regulation: a dynamic water pricing approach. Procs. REFORM International Conference on River and Stream Restoration "Novel Approaches to Assess and Rehabilitate Modified Rivers”. Wageningen.

Haas, N. A., O'Connor, B. L., Hayse, J. W., Bevelhimer, M. S., \& Endreny, T. A. 2014.

Analysis of daily peaking and run-of-river operations with flow variability metrics, considering subdaily to seasonal time scales. JAWRA Journal of the American Water Resources Association, 50(6), 1622-1640.

Huet, M. 1953. Biologie, profils en long et en travers des eaux courantes. Bulletin Français de Pisciculture, 175, 41-53.

Ibarra, G., De la Fuente, A., Contreras, M. 2015. Effects of hydropeaking on the hydrodynamics of a stratified reservoir: the Rapel Reservoir case study. Journal of Hydraulic Research, 53(6), 760-772.

Lundquist, J. D., Cayan, D. R. 2002. Seasonal and spatial patterns in diurnal cycles in streamflow in the western United States. Journal of Hydrometeorology, 3(5), 591-603.

Macdonald-Ross, M. 1977. How numbers are shown. AV Communication Review, 25(4), 359-409.

Meile, T., Boillat, J. L., Schleiss, A. J. 2011. Hydropeaking indicators for characterization of the Upper-Rhone River in Switzerland. Aquatic Sciences, 73(1), 171-182.

Moog, O. 1993. Quantification of daily peak hydropower effects on aquatic fauna and management to minimize environmental impacts. Regulated Rivers Research Management, 8, 5-14.

Morrison, H.A., Smokorowski, K.E. 2000. The Applicability of Various Frameworks and Models for Assessing the Effects of Hydropeaking on the Productivity of Aquatic Ecosystems. Canadian Technical Report of Fisheries and Aquatic Sciences No. 2322.

Olden, J. D., and Poff, N. L. 2003. Redundancy and the choice of hydrologic indices for characterizing streamflow regimes. River Research and Applications, 19(2), 101-121. 
Onwuegbuzie, A. J., \& Dickinson, W. B. 2008. Mixed methods analysis and information visualization: Graphical display for effective communication of research results. The Qualitative Report, 13(2), 204-225.

Parasiewicz, P. 2008. Application of MesoHABSIM and target fish community approaches to restoration of the Quinebaug River, Connecticut and Massachusetts, USA. River Research and Applications, 24(4), 459-471.

Poff, N.L., Allan, J.D., Bain, M.B., Karr, J.R., Prestegaard, K.L., Richter, B.D., Sparks, R.E., Stromberg, J.C. 1997. The natural flow regime: a paradigm for river conservation and restoration. BioScience, 47, 769-784.

R Core Team 2016. R: A language and environment for statistical computing. R Foundation for Statistical Computing, Vienna, Austria.

Renöfält, B.M., Jansson, R., Nilsson, C. 2010. Effects of hydropower generation and opportunities for environmental flow management in Swedish riverine ecosystems. Freshwater Biology, 55, 49-67.

Richter, B., J. Baumgartner, J. Powell, and D. Braun. 1996. A method for assessing hydrologic alteration within ecosystems, Conserv. Biol., 10, 1163- 1174, doi:10.1046/j.1523 1739.1996.10041163.x.

Richter, B., J. Baumgartner, R. Wigington, D. Braun, and J. Powell. 1998. A spatial assessment of hydrologic alteration within a river network, Regul. Riv., 14(4), 329-340, doi:10.1002/(SICI)1099-1646(199807/08)14:4<329:AID-RRR505>3.0.CO;2-E.

Richter, B.D., Baumgartner, J.V., Wigington, R., Braun, D.P. 1997. How much water does a river need? Freshwater Biology, 37: 231-249.

Richter, B.D., Baumgartner, J.V., Wigington, R., Braun, D.P. 1997. How much water does a river need? Freshwater Biology, 37: 231-249.Saltveit, S. J., Halleraker, J. H., Arnekleiv, J. V., \& Harby, A. 2001. Field experiments on stranding in juvenile Atlantic salmon (Salmo salar) and brown trout (Salmo trutta) during rapid flow decreases caused by

hydropeaking. Regulated Rivers: Research \& Management, 17(4-5), 609-622. 
Sauterleute, J. F., \& Charmasson, J. 2014. A computational tool for the characterisation of rapid fluctuations in flow and stage in rivers caused by hydropeaking. Environmental Modelling \& Software, 55, 266-278.

Southwood, T. R. E. 1977. Habitat, the templet for ecological strategies? The Journal of Animal Ecology, 46, 337-365.

Tufte, E. R. 2001. The visual display of quantitative information ( $2^{\text {nd }}$ ed.). Cheshire, Connecticut: Graphics Press.

Vollset, K. W., Skoglund, H., Wiers, T., \& Barlaup, B. T. 2016. Effects of hydropeaking on the spawning behaviour of Atlantic salmon Salmo salar and brown trout Salmo trutta. Journal of fish biology, 88(6), 2236-2250.

Wainer, H. 1992. Understanding graphs and tables. Educational researcher, 21(1), 14-23.

White, M. A., Schmidt, J. C., Topping, D. J. 2005. Application of wavelet analysis for monitoring the hydrologic effects of dam operation: Glen Canyon Dam and the Colorado River at Lees Ferry, Arizona. River Research and Applications, 21(5), 551-565.

Zimmerman, J. K., Letcher, B. H., Nislow, K. H., Lutz, K. A., Magilligan, F. J. 2010.

Determining the effects of dams on subdaily variation in river flows at a whole-basin

scale. River research and applications, 26(10), 1246-1260.

Zolezzi, G., Bellin, A., Bruno, M.C., Maiolini, B., Siviglia, A. 2009. Assessing hydrological alterations at multiple temporal scales: Adige River. Italy. Water Resourses Research 45(12):W12421. doi:10. 1029/2008WR007266. 


\section{Figure captions}

Figure 1.- Example of a graphical representation of the frequency of occurrence (y axis in [a], $[\mathrm{b}],[\mathrm{c}] ; \mathrm{z}$ axis in [d], [e], [f]) of a given value of the variable standardized hourly flow (unitless) (x axis in [a], [b], [c]; y axis in [d], [e], [f]) at a given day i (graphs [a], [b], [c]), and along the year (x axis) (graphs [d], [e], [f]).

Figure 2. Graphical representation of the frequency of occurrence and calculated impact (z axes) of flow variables (y axis, range of values between percentiles 5 and 95 of both altered and free flow hourly observations) along the year (x axis) at Ume/Harrsele and Vindel/Granaker: [a] hourly flow, Qst (unitless); [b] daily amplitude of recorded hourly flows, amplitude_Qst_day (daily maximum minus daily minimum; unitless); [c] rate of change of flows between two consecutive hourly records, decrease_slope_Qst (h-1); and [d] number of hourly flow reversals (decrease to increase, and increase to decrease) per day, reversals_day. Dashed lines delimit the range of values between percentiles 5 and 95 of the hourly observations at the free flow site, $r$.

Figure 3. Graphical representation of the frequency of occurrence and calculated impact (z axes) of flow variables (y axis, range of values between percentiles 5 and 95 of both altered and free flow hourly observations) along the year (x axis) at Ume/Grundfors and Vindel/Sorsele: [a] instantaneous hourly flow, Qst (unitless); [b] daily amplitude of recorded hourly flows, amplitude_Qst_day (daily maximum minus daily minimum; unitless); [c] rate of change of flows between two consecutive hourly records, decrease_slope_Qst (h-1); and [d] number of hourly flow reversals (decrease to increase, and increase to decrease) per day, reversals_day. Dashed lines delimit the range of values between percentiles 5 and 95 of the hourly observations at the free flow site, $r$.

Figure 4. Graphical representation of the frequency of occurrence and calculated impact (z axes) of flow variables (y axis, range of values between percentiles 5 and 95 of both altered and free flow hourly observations) along the year (x axis) at Colorado 2003-11 and 
Colorado 1943-51: [a] instantaneous hourly flow, Qst (unitless); [b] daily amplitude of recorded hourly flows, amplitude_Qst_day (daily maximum minus daily minimum; unitless); [c] rate of change of flows between two consecutive hourly records, decrease_slope_Qst (h-1); and [d] number of hourly flow reversals (decrease to increase, and increase to decrease) per day, reversals_day. Dashed lines delimit the range of values between percentiles 5 and 95 of the hourly observations at the free flow site, $r$.

Figure 5. Graphical representation of the frequency of occurrence and calculated impact ( $\mathrm{z}$ axes) of flow variables (y axis, range of values between percentiles 5 and 95 of both altered and free flow hourly observations) along the year (x axis) at Noce and Vermigliana Rivers: [a] instantaneous hourly flow, Qst (unitless); [b] daily amplitude of recorded hourly flows, amplitude_Qst_day (daily maximum minus daily minimum; unitless); [c] rate of change of flows between two consecutive hourly records, decrease_slope_Qst (h1 ); and [d] number of hourly flow reversals (decrease to increase, and increase to decrease) per day, reversals_day. Dashed lines delimit the range of values between percentiles 5 and 95 of the hourly observations at the free flow site, $r$. 

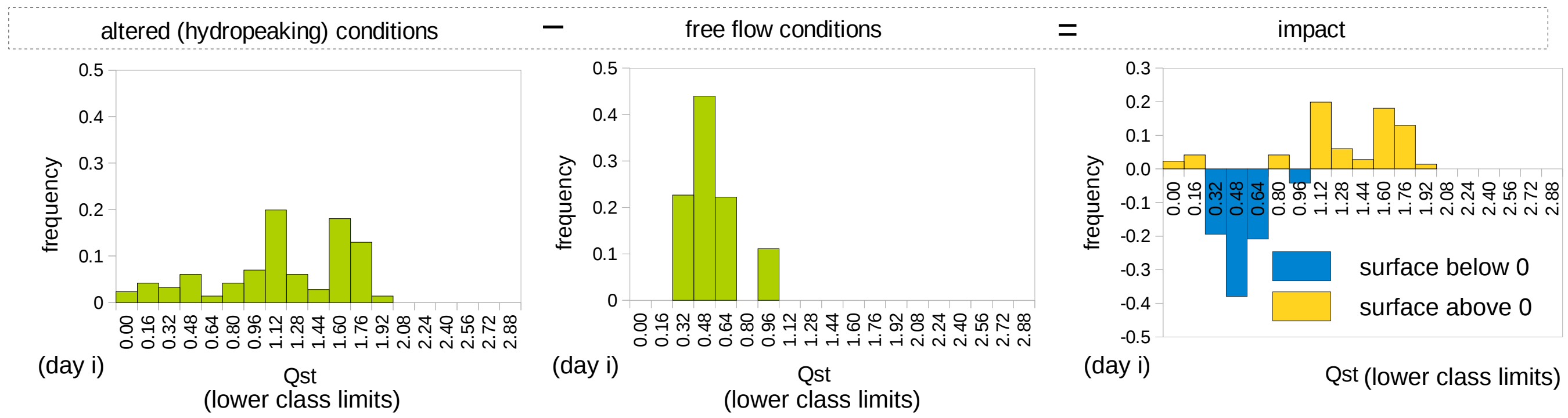

Aggregate daily results into a year graph \& plot a smooth approximation of frequency (z) against Julian day $(x)$ and the value class of the variable (y) (e.g standardized hourly flow, Qst).
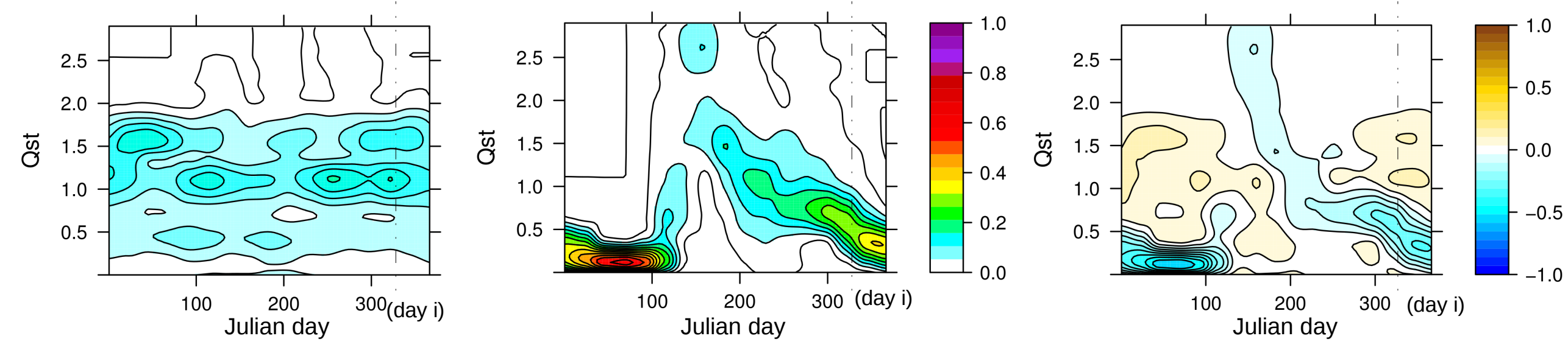
Table 1.- Location and Characteristics of the Case Study rivers: (R) Regulated reaches by Hydropeaking; (FF) Free flowing reaches for references.

\begin{tabular}{|c|c|c|c|c|c|c|c|c|}
\hline River name & Ume (R) & Vindel (FF) & Ume (R) & Vindel (FF) & Colorado (R) & Colorado (FF) & Noce (R) & $\begin{array}{l}\text { Vermigliana } \\
\text { (FF) }\end{array}$ \\
\hline Location & Grundfors & Sorsele & Harrsele & Granaker & Lees Ferry & Lees Ferry & Male & Vermiglio \\
\hline Country & Sweden & Sweden & Sweden & Sweden & USA & USA & Italy & Italy \\
\hline$X, Y$ Coordinates & $\begin{array}{l}64.960366^{\circ} \mathrm{N} \\
17.578501^{\circ} \mathrm{E} \\
\end{array}$ & $\begin{array}{l}65.534925^{\circ} \mathrm{N} \\
17.535463^{\circ} \mathrm{E}\end{array}$ & $\begin{array}{l}64.000132^{\circ} \mathrm{N} \\
19.585188^{\circ} \mathrm{E} \\
\end{array}$ & $\begin{array}{l}64.239804^{\circ} \mathrm{N} \\
19.668881^{\circ} \mathrm{E}\end{array}$ & $\begin{array}{r}36.932770^{\circ} \mathrm{N} \\
111.479337^{\circ} \mathrm{W} \\
\end{array}$ & $\begin{array}{r}36.932770^{\circ} \mathrm{N} \\
111.479337^{\circ} \mathrm{W} \\
\end{array}$ & $\begin{array}{l}46.3472444^{\circ} \mathrm{N} \\
10.9138322^{\circ} \mathrm{E} \\
\end{array}$ & $\begin{array}{c}46.29784167^{\circ} \mathrm{N} \\
10.7019525^{\circ} \mathrm{E} \\
\end{array}$ \\
\hline Mean annual discharge $\left(\mathrm{m}^{3} / \mathrm{s}\right)$ & 197 & 119 & 234 & 176 & 358 & 465 & 12 & 2 \\
\hline Dam name and closing date & $\begin{array}{c}\text { Grundfors } \\
1958\end{array}$ & - & $\begin{array}{c}\text { Harrsele } \\
2006\end{array}$ & - & $\begin{array}{c}\text { Glen Canyon } \\
1964\end{array}$ & - & $\begin{array}{c}\text { Pian Palù \& } \\
\text { Careser }\end{array}$ & - \\
\hline Dam head $(m)$ & 35.3 & - & 55 & - & 156 & - & 51.5 & - \\
\hline Reservoir storage capacity $\left(\mathrm{hm}^{3}\right)$ & & - & & - & 63000 & - & 15.5 & - \\
\hline Total Power (MW) & 103.5 & - & 223 & - & 1320 & - & 58 & - \\
\hline Annual production (GWh/year) & 492 & - & 970 & - & 3209 & - & 179.4 & - \\
\hline Gauging station name/code & Grund. dam & So2 (2238) & Harr. Dam & Gran (2237) & 9380000 & 9380000 & Male & Vermiglio \\
\hline Flow data series & 2003-2011 & 2003-2011 & 2003-2011 & 2003-2011 & 2003-2011 & 1943-1951 & 2003-2011 & 2003-2011 \\
\hline
\end{tabular}




\begin{tabular}{|c|c|c|c|c|c|c|c|c|}
\hline River name & Ume (R) & Vindel (FF) & Ume (R) & Vindel (FF) & Colorado (R) & Colorado (FF) & Noce (R) & $\begin{array}{c}\text { Vermigliana } \\
\text { (FF) }\end{array}$ \\
\hline Location & Grundfors & Sorsele & Harrsele & Granaker & Lees Ferry & Lees Ferry & Male & Vermiglio \\
\hline Country & Sweden & Sweden & Sweden & Sweden & USA & USA & Italy & Italy \\
\hline$X, Y$ Coordinates & $\begin{array}{l}64.960366^{\circ} \mathrm{N} \\
17.578501^{\circ} \mathrm{E}\end{array}$ & $\begin{array}{l}65.534925^{\circ} \mathrm{N} \\
17.535463^{\circ} \mathrm{E}\end{array}$ & $\begin{array}{l}64.000132^{\circ} \mathrm{N} \\
19.585188^{\circ} \mathrm{E}\end{array}$ & $\begin{array}{l}64.239804^{\circ} \mathrm{N} \\
19.668881^{\circ} \mathrm{E}\end{array}$ & $\begin{array}{c}36.932770^{\circ} \mathrm{N} \\
111.479337^{\circ} \mathrm{W}\end{array}$ & $\begin{array}{c}36.932770^{\circ} \mathrm{N} \\
111.479337^{\circ} \mathrm{W}\end{array}$ & $\begin{array}{l}46.3472444^{\circ} \mathrm{N} \\
10.9138322^{\circ} \mathrm{E}\end{array}$ & $\begin{array}{c}46.29784167^{\circ} \mathrm{N} \\
10.7019525^{\circ} \mathrm{E}\end{array}$ \\
\hline Mean annual discharge $\left(\mathrm{m}^{3} / \mathrm{s}\right)$ & 197 & 119 & 234 & 176 & 358 & 465 & 12 & 2 \\
\hline Dam name and closing date & $\begin{array}{c}\text { Grundfors } \\
1958 \\
\end{array}$ & - & $\begin{array}{c}\text { Harrsele } \\
2006 \\
\end{array}$ & - & $\begin{array}{c}\text { Glen Canyon } \\
1964 \\
\end{array}$ & - & $\begin{array}{c}\text { Pian Palù \& } \\
\text { Careser }\end{array}$ & - \\
\hline Dam head $(\mathrm{m})$ & 35.3 & - & 55 & - & 156 & - & 51.5 & - \\
\hline Reservoir storage capacity $\left(\mathrm{hm}^{3}\right)$ & & - & & - & 63000 & - & 15.5 & - \\
\hline Total Power (MW) & 103.5 & - & 223 & - & 1320 & - & 58 & - \\
\hline Annual production (GWh/year) & 492 & - & 970 & - & 3209 & - & 179.4 & - \\
\hline Gauging station name/code & Grund. dam & So2 (2238) & Harr. Dam & Gran (2237) & 9380000 & 9380000 & Male & Vermiglio \\
\hline Flow data series & $2003-2011$ & 2003-2011 & $2003-2011$ & 2003-2011 & 2003-2011 & $1943-1951$ & $2003-2011$ & 2003-2011 \\
\hline
\end{tabular}


Table 2.- Comparison of hydropeaking impacts in the case studies through the values of three analogous metrics identified using Sauterleute \& Charmasson $(\mathrm{S})$ ( $F$ is the peaking amplitude; $R$ is the mean rate of standardized flow decrease; and $N$ is the mean number of daily rapid decreases) parameters and those proposed by the graphical method (GM) (impact calculated from the comparison of graphs for variables: amplitude_Qst is daily amplitude of recorded hourly flows; decrease_slope_Qst is rate of flow decrease between two consecutive hourly records; and reversals_day is number of hourly flow reversals (decrease to increase, and increase to decrease) per day).

\begin{tabular}{|c|c|c|c|c|c|}
\cline { 2 - 6 } \multicolumn{1}{c|}{} & \multicolumn{1}{c|}{ River name } & Ume & Ume & Colorado & Noce \\
\cline { 2 - 6 } \multicolumn{1}{c|}{ Location } & Harrsele & Grundfors & Lees Ferry & Male \\
\cline { 2 - 6 } & \multicolumn{1}{|c}{ Country } & Sweden & Sweden & USA & Italy \\
\hline \hline $\mathrm{GM}$ & amplitude_Qst & 7.72 & 2.24 & 1.36 & 0.109 \\
\hline $\mathrm{S}$ & F= Qmax/Qmin & 107.8 & 47.1 & 1.6 & 1.5 \\
\hline $\mathrm{GM}$ & decrease_slope_Qst $\left(\mathrm{h}^{-1}\right)$ & 7.96 & 1.54 & 0.9 & 0.035 \\
\hline $\mathrm{S}$ & $R=$ mean Slope $\left(\mathrm{h}^{-1}\right)$ & 0.1725 & 0.1395 & 0.0562 & 0.0656 \\
\hline $\mathrm{GM}$ & reversals_day $\left(\mathrm{d}^{-1}\right)$ & 2.83 & 0.22 & 1.51 & 0.092 \\
\hline $\mathrm{S}$ & $\mathrm{N}\left(\mathrm{d}^{-1}\right)$ & 1.07 & 0.62 & 0.94 & 0.66 \\
\hline
\end{tabular}




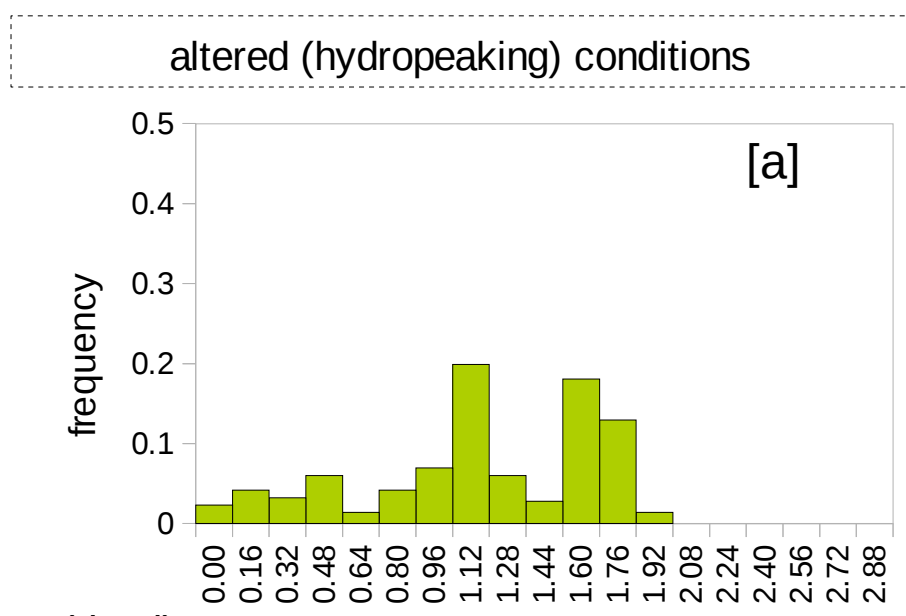

(day i)

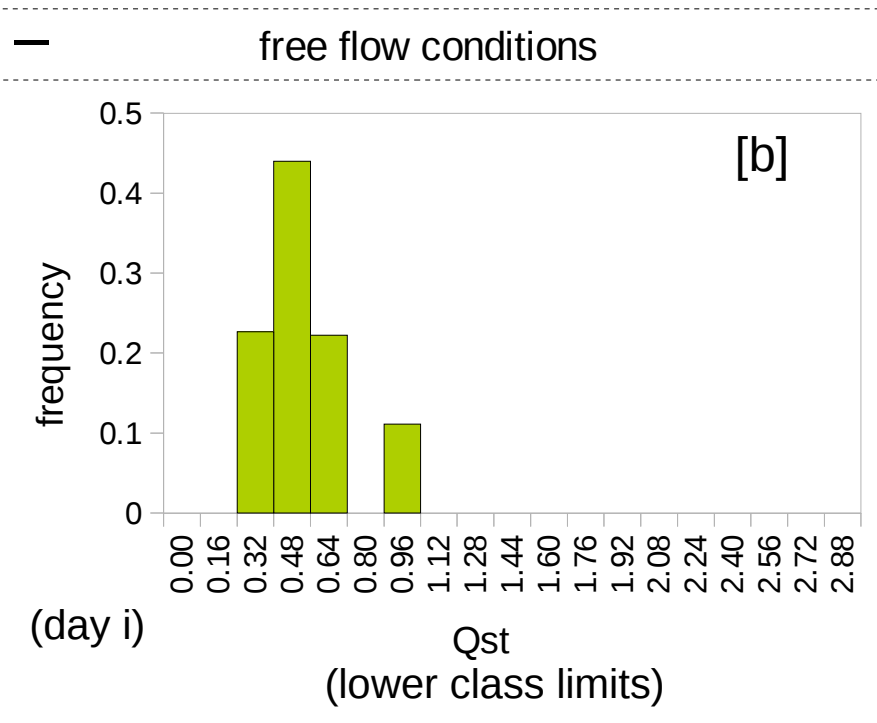

$=$

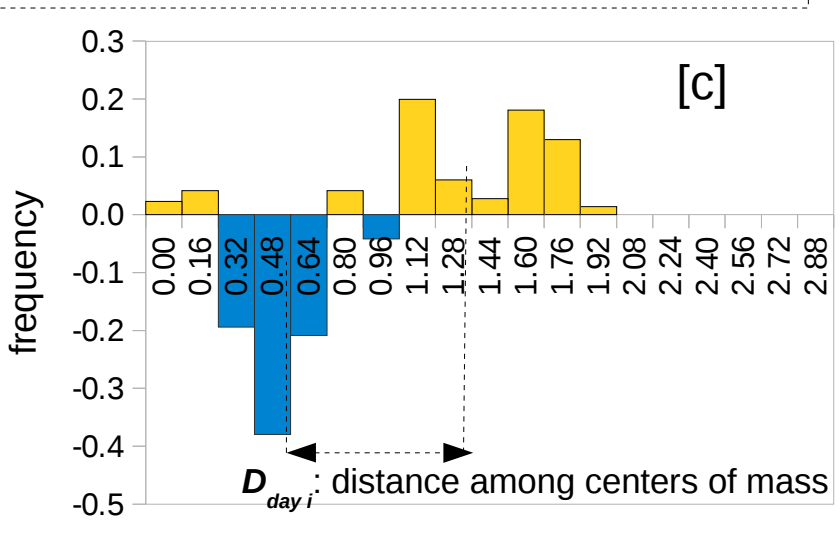

(day i)

Qst (lower class limits)

$A_{\text {day } i:}^{\text {neg. }}$ surface below 0 $A_{\text {day } i}^{\text {pos. }}$ : surface above 0

[d]

[e]

[f]
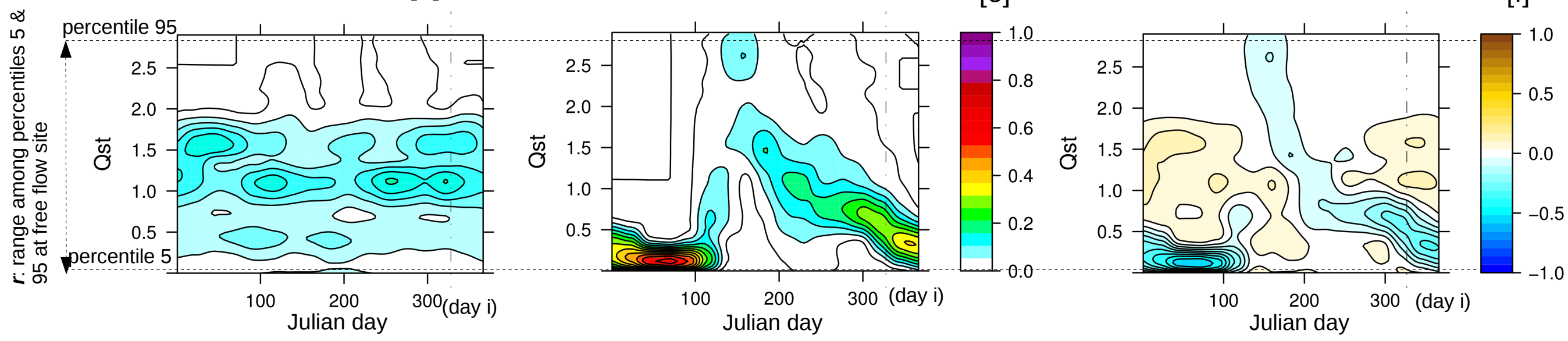
Figure 2

Umeå Harrsele (altered) - Vindel Granaker (free flow) =

impact
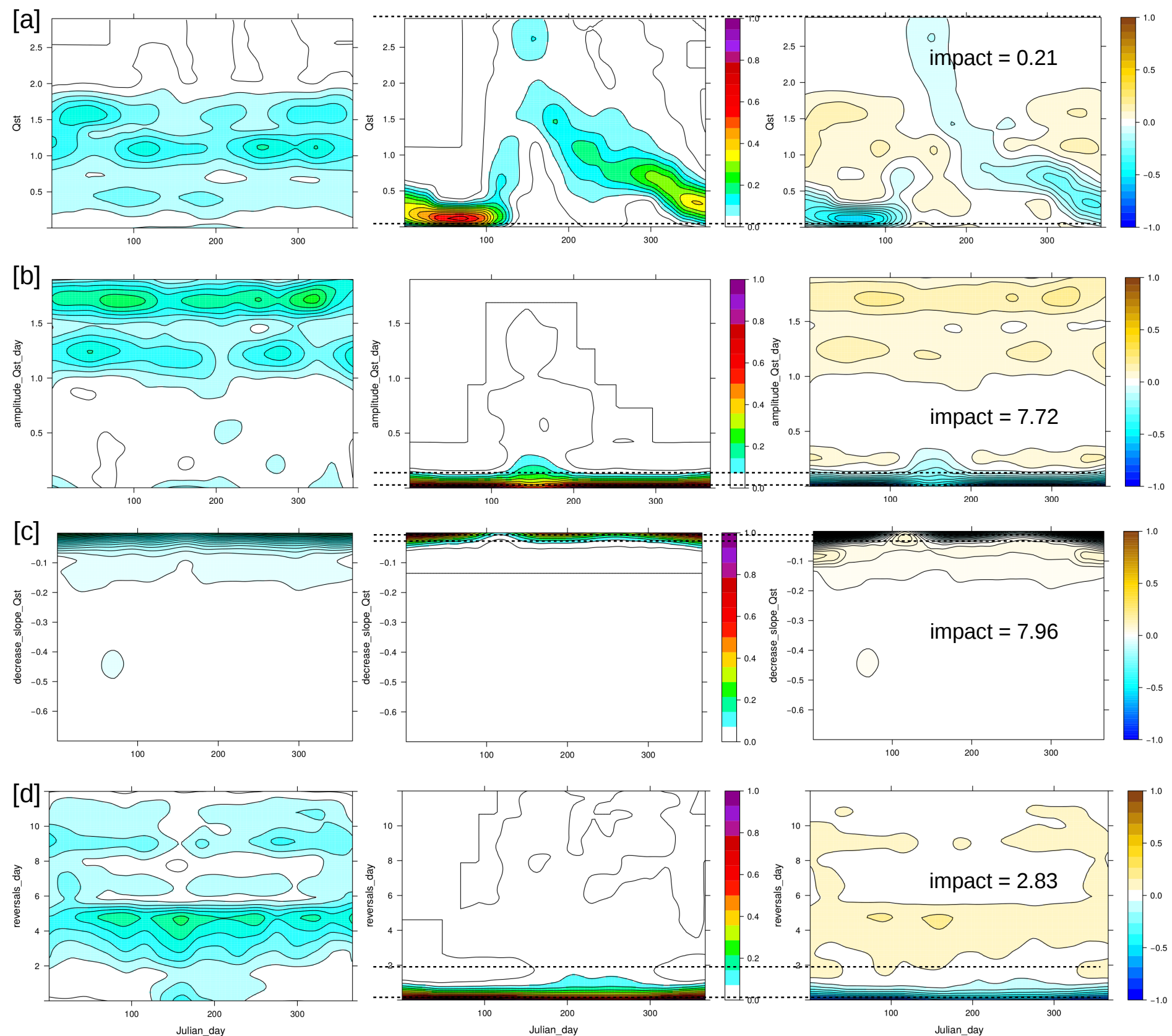
Figure 3

Umeå Grundfors (altered) - Vindel Sorsele (free flow) =

impact
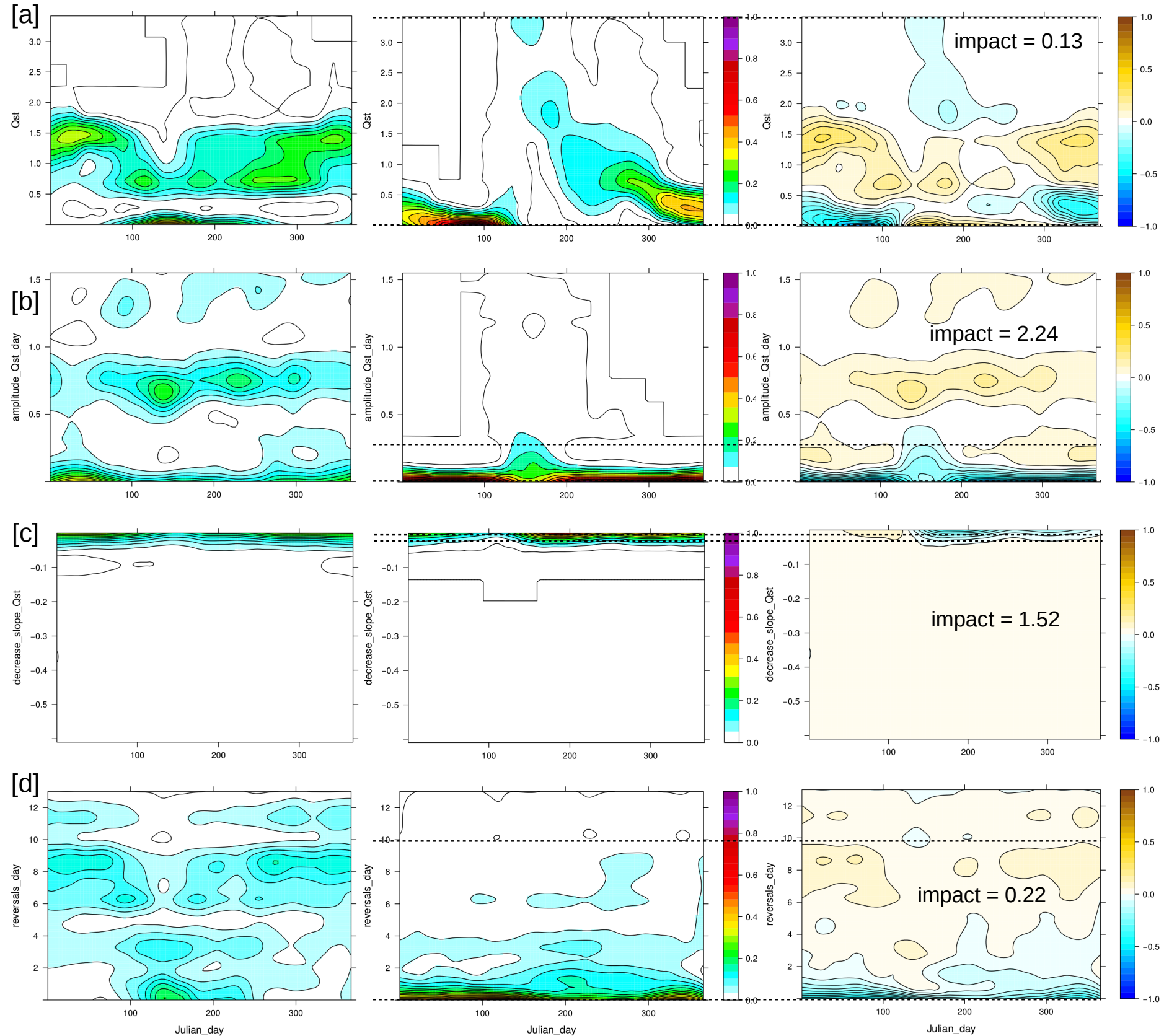
Colorado 2003-11 (altered) - Colorado 1943-51 (free flow) =

impact
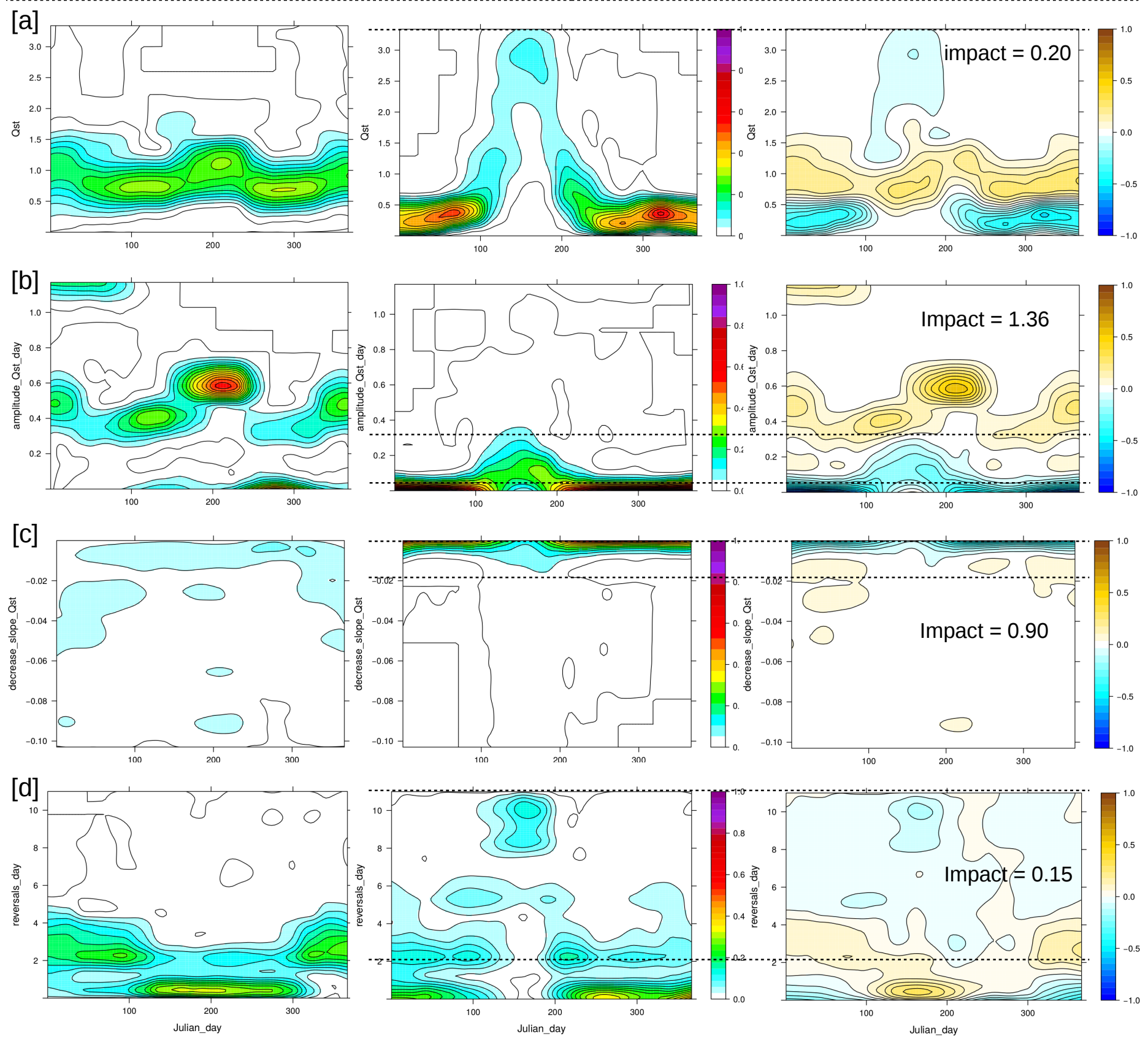
Figure 5

\section{Male (altered)}
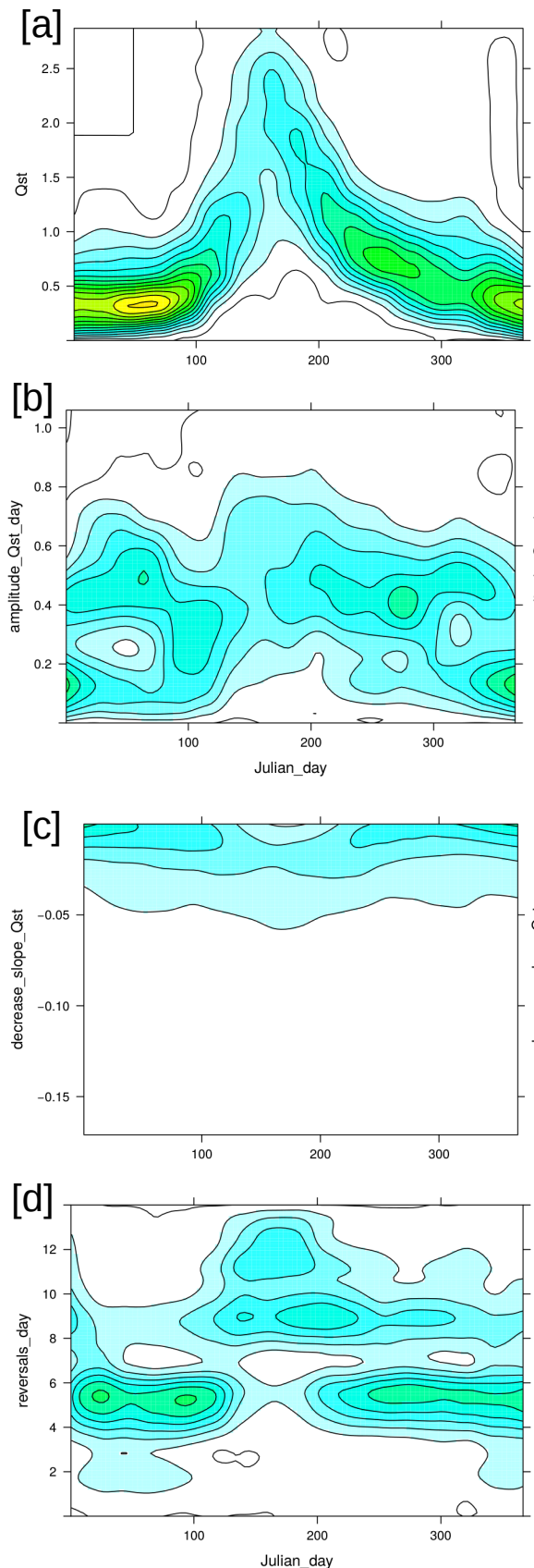

- Vermigliana (free flow)

$=$

impact
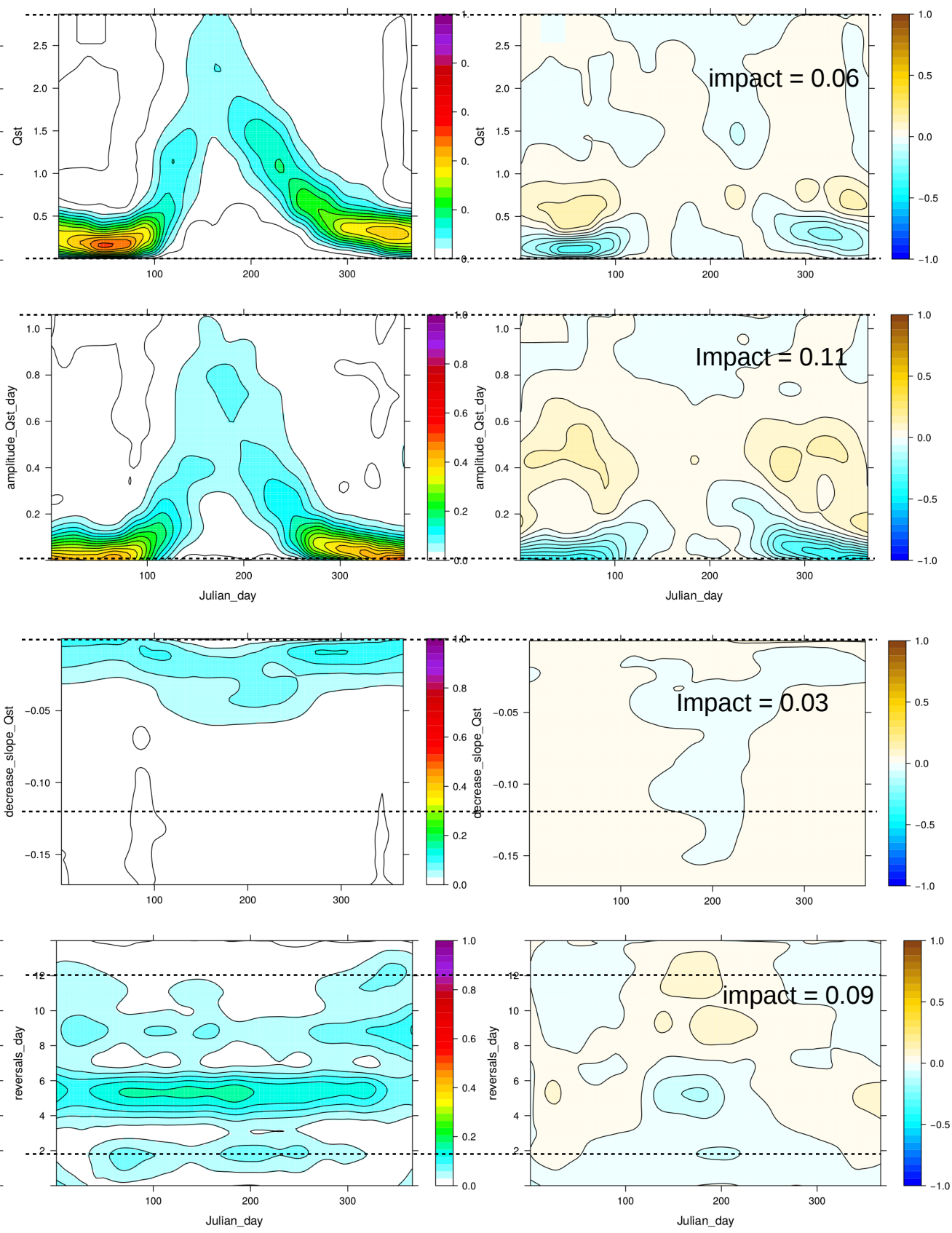